Article

\title{
Fractional Cover Mapping of Invasive Plant Species by Combining Very High-Resolution Stereo and Multi-Sensor Multispectral Imageries
}

\author{
Siddhartha Khare ${ }^{1,2, *}$, Hooman Latifi ${ }^{3,4, *}$, Sergio Rossi ${ }^{1,5}$ and Sanjay Kumar Ghosh ${ }^{2}$ \\ 1 Département des Sciences Fondamentales, Université du Québec à Chicoutimi, \\ Saguenay, QC G7H 2B1, Canada \\ 2 Department of Civil Engineering, Geomatics Engineering Division, Indian Institute of Technology, \\ Roorkee 247667, India \\ 3 Department of Photogrammetry and Remote Sensing, Faculty of Geodesy and Geomatics Engineering, \\ K. N. Toosi University of Technology, Tehran 19967-15433, Iran \\ 4 Department of Remote Sensing, University of Würzburg, D-97074 Würzburg, Germany \\ 5 Key Laboratory of Vegetation Restoration and Management of Degraded Ecosystems, \\ Guangdong Provincial Key Laboratory of Applied Botany, South China Botanical Garden, \\ Chinese Academy of Sciences, Guangzhou 510650, China \\ * Correspondence: siddhartha.khare1@uqac.ca (S.K.); hooman.latifi@kntu.ac.ir (H.L.)
}

Received: 21 May 2019; Accepted: 26 June 2019; Published: 27 June 2019

\begin{abstract}
Invasive plant species are major threats to biodiversity. They can be identified and monitored by means of high spatial resolution remote sensing imagery. This study aimed to test the potential of multiple very high-resolution (VHR) optical multispectral and stereo imageries (VHRSI) at spatial resolutions of 1.5 and $5 \mathrm{~m}$ to quantify the presence of the invasive lantana (Lantana camara $\mathrm{L}$.) and predict its distribution at large spatial scale using medium-resolution fractional cover analysis. We created initial training data for fractional cover analysis by classifying smaller extent VHR data (SPOT-6 and RapidEye) along with three dimensional (3D) VHRSI derived digital surface model (DSM) datasets. We modelled the statistical relationship between fractional cover and spectral reflectance for a VHR subset of the study area located in the Himalayan region of India, and finally predicted the fractional cover of lantana based on the spectral reflectance of Landsat- 8 imagery of a larger spatial extent. We classified SPOT- 6 and RapidEye data and used the outputs as training data to create continuous field layers of Landsat- 8 imagery. The area outside the overlapping region was predicted by fractional cover analysis due to the larger extent of Landsat-8 imagery compared with VHR datasets. Results showed clear discrimination of understory lantana from upperstory vegetation with $87.38 \%$ (for SPOT-6), and $85.27 \%$ (for RapidEye) overall accuracy due to the presence of additional VHRSI derived DSM information. Independent validation for lantana fractional cover estimated root-mean-square errors (RMSE) of $11.8 \%$ (for RapidEye) and 7.22\% (for SPOT-6), and $R^{2}$ values of 0.85 and 0.92 for RapidEye $(5 \mathrm{~m})$ and SPOT-6 $(1.5 \mathrm{~m})$, respectively. Results suggested an increase in predictive accuracy of lantana within forest areas along with increase in the spatial resolution for the same Landsat- 8 imagery. The variance explained at $1.5 \mathrm{~m}$ spatial resolution to predict lantana was $64.37 \%$, whereas it decreased by up to $37.96 \%$ in the case of $5 \mathrm{~m}$ spatial resolution data. This study revealed the high potential of combining small extent VHR and VHRSI- derived 3D optical data with larger extent, freely available satellite data for identification and mapping of invasive species in mountainous forests and remote regions.
\end{abstract}

Keywords: Lantana camara; SPOT-6; RapidEye; 3D; DSM; Fractional cover analysis 


\section{Introduction}

Various studies have revealed the importance of plant biodiversity for the functioning of an ecosystem, which is closely connected with human activities [1,2]. However, apart from its significance for terrestrial ecosystems, it is much more important to emphasize the qualitative and quantitative changes or threats to plant biodiversity [3]. A proper regular and effective monitoring system is evidently required to characterize these changes. With the ability to view terrestrial vegetation from space, remote sensing has tremendous potential to provide long-term, continuous solutions at different spatial, temporal and spectral resolutions [4-6]. Satellite remote sensing datasets can represent a great opportunity when field-based observations are impossible or hampered [7-9]. High-resolution satellite data have enabled the development of species-level distribution maps along with three-dimensional (3D) information on forest structural traits such as species composition, canopy diameter, and distribution of age-classes [10]. In recent years, interest in employing multi-spectral, multi-temporal high and very high spatial resolution data to study biological invasions in plant communities has grown considerably [11].

Topographic information derived from remote sensing data enhances differentiation of plant or tree species that are spectrally similar. However, during the last decade, airborne laser scanning has been the primary data source to capture 3D information on forest vertical structure [12-14]. This tool is expensive, and possibly unavailable for developing countries [15]. In recent years, the improvement in space technology has reduced the gap in terms of spatial resolution (up to $30 \mathrm{~cm}$ ground sample distance) between aerial and satellite imagery [16]. Moreover, high-resolution digital surface models (DSM) are now more widely available through stereo imaging capacities and a worldwide access to very high-resolution (VHR) satellite data.

Over the last decade, satellite data for large areas provide information only on presence or absence of forests types or tree cover percentages. Prominently, AVHRR, MODIS or Landsat-based continuous (fractional) land-cover maps are available at coarser and medium spatial resolutions for forest cover change [17-19]. Other products also provide information, such as NDVI-derived vegetation fractional cover data of Oceansat-2 Ocean Color Monitor [20] for India and European initiative coordinated information on the environment (CORINE) derived land cover inventory data for coniferous and broadleaf tree species groups [21]. A review and comparison of various land cover products derived from satellite data can be found in [21]. These data provide an overview of forest types and species distribution at coarser $(250 \mathrm{~m}$ to $1 \mathrm{~km})$ and medium $(30 \mathrm{~m})$ spatial resolutions, but detailed information at finer spatial levels like plant species or trees is still lacking.

Previous studies analyzed detailed level species distribution for mapping and identification, utilizing VHR remote sensing data such as IKONOS or WorldView-2 (WV2) [22-27]. Similarly, a few studies with spatial resolution $<5 \mathrm{~m}$ addressed mapping of invasive plant species using IKONOS [28], Cartosat-I [29] and Pléiades -1A [30] in the western Himalayan region of India. However, such studies can be only implemented in small areas, due to the high cost and scarcity of VHR and VHR stereo imagery (VHRSI) data compared with medium and coarser spatial resolution data. Thus, detailed studies covering larger geographic areas at higher spatial resolutions are still lacking [31], in particular across the high-altitude, species-rich Indian Himalayan region [32].

An alternative is to develop approaches to estimate the fraction of land cover within each optical pixel, by linking freely available medium spatial resolution (larger extent) with VHR (smaller extent) data. Fractional cover analysis has been subjected to intensive research using different satellite and aerial imageries. Recent studies combined VHR WV-2 with time series Landsat [33], IKONOS with Landsat [34,35] and GeoEye-1 with Landsat data [36] for generation of high spatial resolution fractional cover maps for larger geographical areas. It is thus practically crucial to utilize the combination of VHR with freely available medium spatial resolution datasets such as Landsat or MODIS due to their larger spatial coverage.

In this study, the potential of new-generation VHRSI and VHR multispectral satellite data was tested for classification and fractional cover analysis of an invasive shrub, lantana (Lantana camara L.), which extensively affects the western Himalayan forest in India. Fractional cover analysis was 
suggested to address the issue of estimating lantana distribution in Doon Valley. We aimed to (i) classify VHR SPOT-6 and RapidEye with additional 3D information from VHRSI SPOT-6 generated DSM; (ii) model the statistical relationship between fractional cover and spectral reflectance derived from high spatial resolution maps, and predict the fractional cover of lantana in a larger area based on the spectral reflectance of Landsat 8 imagery; and (iii) compare model performance between Landsat 8-SPOT-6 $(1.5 \mathrm{~m})$ and Landsat 8 -RapidEye $(5 \mathrm{~m})$ fractional cover maps. We expected that Landsat-8-based upscaled lantana species information derived from input classified VHR imageries would provide an appropriate baseline for a fractional cover analysis approach for different types of forest regimes.

\section{Materials and Methods}

\subsection{Study Area}

The study area is located in the western Himalayan region of Doon valley, Uttarakhand, India $\left(29,055^{\prime}\right.$ to $30,030^{\prime} \mathrm{N}$ and $77,035^{\prime}$ to $\left.78,024^{\prime} \mathrm{E}\right)$, at elevations ranging between 500 and $800 \mathrm{~m}$ above sea level (Figure 1). The climate is humid sub-tropical [37]. The temperature ranges between 16.7 and $36{ }^{\circ} \mathrm{C}$ during summer, and between 5.2 and $23.4{ }^{\circ} \mathrm{C}$ in winter [38]. Average annual rainfall is $2025 \mathrm{~mm}$, and is mainly concentrated in the period between June and September. The Doon valley encompasses subtropical moist deciduous forests (MDF) dominated by sal trees (Shorea robusta G.) and Mallotus philippensis Lam., with Clerodendrum infortunatum L. and lantana in the understory. The Lachhiwala and Thano forest areas within the Doon valley were selected for this analysis due to availability of GPS observations of lantana locations in these forest sites.

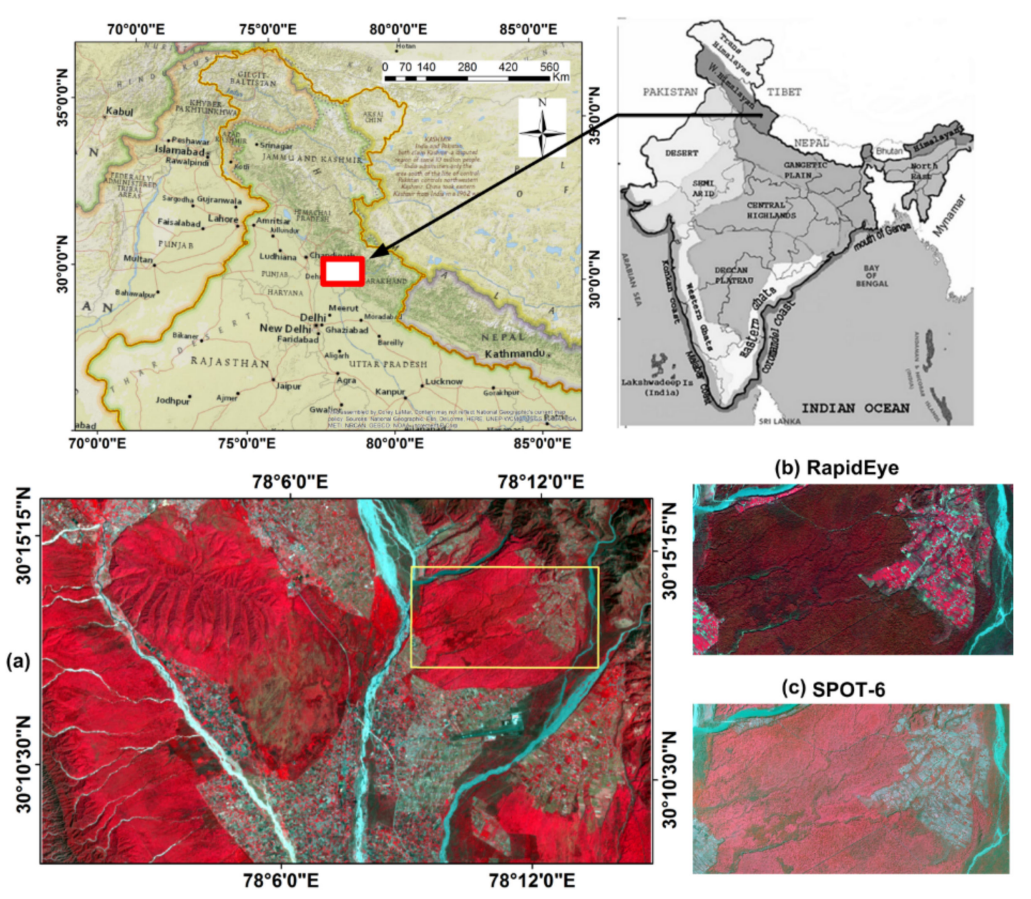

Figure 1. Study area location (a) Landsat-8 imagery with larger extent and yellow box showing the smaller extent of (b) RapidEye and (c) SPOT-6 multispectral imageries.

\subsection{Satellite Data}

We acquired satellite remote sensing data during April 2013, because shedding of leaves of overstory vegetation and visibility of understory vegetation (i.e., lantana) culminates in this month [39,40]. Orthorectified Level-3A, cloud free and pre-processed SPOT-6 imageries (multispectral and Panchromatic (PAN) stereo pair) and RapidEye (multispectral) were acquired (Table 1). The RapidEye sensor has an additional red-edge band with a spectral range of 690-730 nm; further details on the specifications of 
the RapidEye are given in [41]. We applied atmospheric corrections to convert DN values into surface reflectance using ATCOR 3 [42]. Selected vegetation indices (NDVI, MSAVI2 and NDRE) were generated from the surface reflectance values. Pre-processed Level-2, Landsat-8 OLI data were acquired from USGS (United States Geological Survey) for wider coverage (Figure 1). In this paper, four spectral bands (Blue, Green, Red and NIR) of Landsat-8 OLI were applied (Table 1).

Table 1. Details of satellite data used.

\begin{tabular}{cccc}
\hline Satellite & Sensors & Date of Acquisitions & Spatial Resolution $(\mathbf{m})$ \\
\hline SPOT-6 & (Stereo pair PAN) & 5 April 2013 & 1.5 \\
SPOT-6 & (Blue, Green, Red and NIR) & 25 April 2013 & 1.5 \\
RapidEye & (Blue, Green, Red, Red-Edge and NIR) & 12 April 2013 & 5 \\
Landsat-8 OLI & (Blue, Green, Red and NIR) & 11 April 2013 & 30 \\
\hline
\end{tabular}

\subsection{High-Resolution DSM}

The DSM generation algorithm was adopted from [43]. The process comprised the following steps: tie points that were common to stereo pair images were generated using an automatic tie point generation tool. In the case of SPOT-6 imagery, RPC file was used as an input for tie point generation [44]. Tie points appearing within the overlap portion of the left and right images were identified. The resulting output consisted of the image location of tie points appearing within stereo pair rasters. Point cloud data were generated from stereo pairs using the image-matching point cloud generation algorithm eATE (Enhanced Automatic Terrain Extraction), which is an area-based method and uses a normalized cross correlation strategy [15,45] in Erdas Imagine (2015). The point cloud data were then interpolated into raster DSM $[46,47]$ at a spatial resolution of $1.5 \mathrm{~m}$ by a triangulation technique implemented within ArcGIS (2015).

\subsection{Image Classification and Generation of Reference Fractional Cover Data}

Random forest $(\mathrm{RF})$ classification was applied separately on both SPOT-6 and RapidEye multispectral VHR datasets (Figure 2). RF is a bootstrapped approach based on classification and regression trees (CARTs), with implications for both classification and predictive modelling. Detailed information on this algorithm and its application in remote sensing is available in $[48,49]$. The classification was carried out within the RSToolbox library [50] in R [51], following the steps as described by [52]. We generated 10-band stacked images separately for both RapidEye and SPOT-6 imageries along with the ancillary data and used them as input variables for the RF classifier. We stacked 5 spectral bands and 5 ancillary variables for RapidEye, and 4 spectral bands and 6 ancillary variables for SPOT-6.

Ancillary data (Table 2) in the case of classifying SPOT-6 image included (1) the $1.5 \mathrm{~m}$ spatial resolution generated DSM from SPOT-6 stereo pair, (2) slope and aspect calculated from the DSM, (3) texture measures of entropy and contrast derived for NIR and Red bands [53], (4) normalized difference vegetation index (NDVI), and (5) modified soil adjusted vegetation index2 (MASVI2). In the case of the RapidEye data, the ancillary data (Table 2) included (1) resampled 5-m DSM generated from the SPOT-6 stereo pair, (2) resampled slope and aspect calculated from the DSM, (3) texture measures of entropy and contrast derived for the NIR and red-edge bands [53], and (4) NDVI as well as (5) normalized difference red-edge index (NDRE).

Table 2. Global list of variables used as ancillary data.

\begin{tabular}{ll}
\hline \multicolumn{1}{c}{ Variables for Ancillary Data } & \multicolumn{1}{c}{ Associated Satellite Data } \\
\hline DSM (1.5m)-elevation, slope and aspect & SPOT-6 \\
Resampled DSM (5m)-elevation, slope and aspect & RapidEye \\
NDVI & SPOT-6 and RapidEye \\
MSAVI2 & SPOT-6 \\
NDRE & RapidEye \\
Texture measure (Entropy, Contrast) & SPOT-6 (NIR, Red bands) and RapidEye (NIR, Red-edge bands) \\
\hline
\end{tabular}


We followed straightforward rationales in selecting the vegetation indices used in our analysis. NDVI is a reliable proxy of photosynthetic activity and chlorophyll in vegetation [54]. NDRE leverages the information from Red-Edge region and is thus closely related to vegetation health [55] and nitrogen [56] content, and the MSAVI2 has been shown to account for soil background reflectance in different vegetation covers [57].

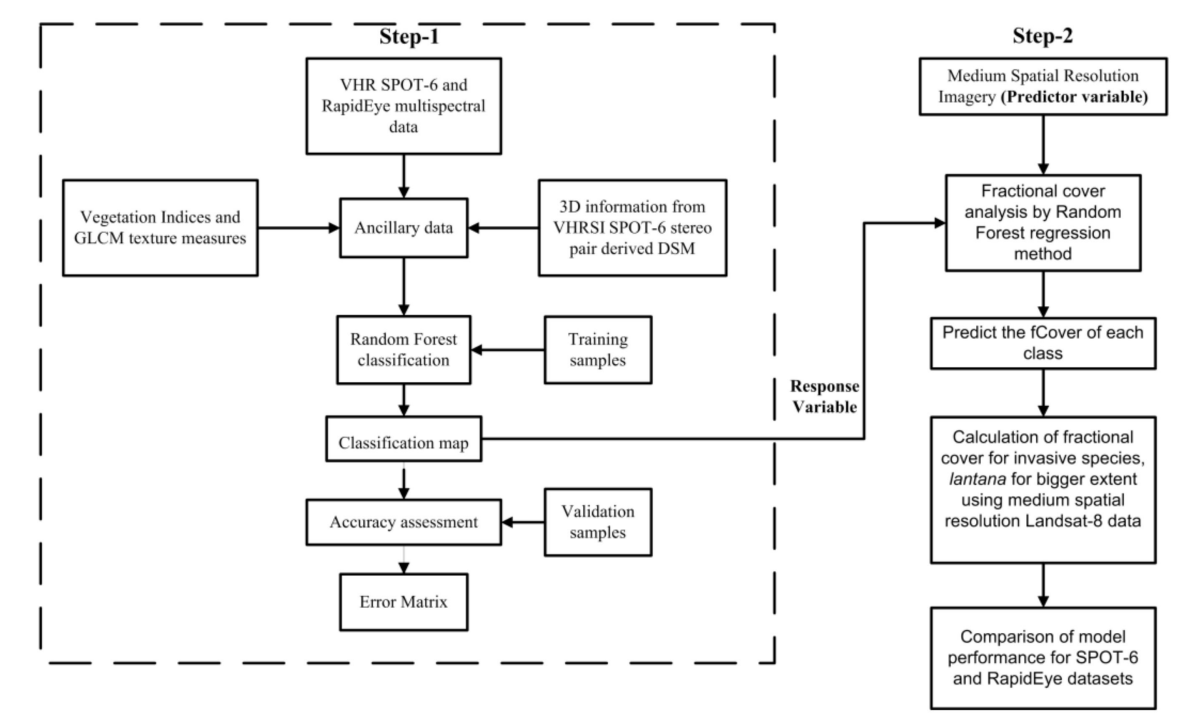

Figure 2. Workflow diagram for classification (Step-1) and fractional cover analysis (Step-2).

For each satellite data set, a total of 2000 random points were distributed throughout the training data from our input variables to grow 400 trees. For every tree, $66 \%$ of the data was used to construct the classification tree, while the remaining 33\% was used for validation using out-of-bag (OOB) error [58]. OOB error was used from a classification accuracy matrix [59] as a tool to evaluate the final predictions with the withheld data and a variable importance plot to assess the relative importance of the 10 bands used in each classification [48]. Independence of the accuracy assessment was ensured by applying a 5-fold cross-validation with a 10\% withhold of the training data [60], in addition to a post-classification accuracy assessment. Using this framework, the MDF and its surrounding locations were classified for SPOT-6 and RapidEye multispectral data. Post-classification accuracy assessment was conducted by generating stratified random points within each vegetation class. The points were manually attributed to their actual land-cover type through visual interpretation of Google Earth imagery [61] and to their attributed class by intersecting with the classified satellite image. A classification accuracy matrix was constructed to compare the reference class with the one assigned by the classifier and calculate the overall accuracy (OA), producer's and user's accuracies [62]. The Kappa coefficient was additionally calculated as a discrete multivariate statistic [62]. Lastly, variable importance as mean decrease in accuracy for each class was computed for classified RapidEye and SPOT-6 data. Mean decrease in accuracy measures the amount of mean standard error as decreased by removing a given input variable and it is calculated according to the increase in prediction error when OOB data (cases left out of the bootstrap sample) for that variable are permuted while all other variables are left unchanged [48].

\subsection{Estimation of Fractional Cover for Larger Extent Using Landsat-8}

Fractional cover maps of lantana for the Lachhiwala and Thano forests were generated by RF after creation of a reference dataset [33]. Fractional cover analysis was performed by taking the classified RapidEye and SPOT-6 imagery into account as predictors (Figure 2). We used the routine implemented within the RStoolbox [50]. Fractional cover extracts pixel values in a classified VHR image that corresponds to a random selection of medium spatial resolution pixels. It then calculates 
the percentage of classified image pixels that represent the cover type of interest. For example, with the $1.5 \mathrm{~m}$ pixel size of SPOT-6 VHR imagery and $30 \mathrm{~m}$ spatial resolution of Landsat-8, the sampling process uses 400 blocks of the $1.5-\mathrm{m}$ resolution pixels corresponding to a single $30-\mathrm{m}$ pixel and calculates the percentage of $1.5-\mathrm{m}$ pixels that belong to the area covered by lantana. That is, with 100 pixels of lantana and 300 other class pixels, the value given for the output pixel would be 0.25 , since $25 \%$ of the total amount of pixels belongs to lantana cover.

\section{Results and Discussion}

\subsection{Classification of Combined Multispectral VHR and VHRSI DSM Data}

VHRSI DSM is shown in Figure 3. Results of classifying SPOT-6 and RapidEye imageries in the MDF showed differences in cover estimation for all categories, in particular for sal tree, agriculture and lantana. This was related to the intrinsic difference in spatial resolutions (Figure 4). For example, both user accuracy (measure for commission) and producer accuracy (measure for omission) for tree-dominated classes (sal tree and lantana) were significantly higher for higher resolution SPOT-6 data, whereas lower resolution RapidEye data classification excessed in both measures for more homogeneously distributed agriculture class. In addition, a more contiguous and widely distributed lantana cover was estimated by SPOT-6. Overall, SPOT-6 and RapidEye showed 87.38 and $85.27 \%$ classification accuracy when tested by independent validation (Tables 3 and 4). Results were partially subjected to omission and commission errors. For lantana, 60 pixels in SPOT-6 and 48 pixels in RapidEye were assigned to shadow, probably because the larger sal trees were mainly growing on north-west slopes, and thereby casting shadows over the lantana cover (Tables 3 and 4). It was observed from previous ground and remote sensing-based studies that selected forest sites were mainly dominated by lantana as understory components $[29,30,63]$. In addition, lantana is an effective competitor with native plant species and is capable of interrupting the regeneration process of other indigenous species by reducing germination [63]. Therefore, GPS points and Google Earth VHR imagery were used to derive training data to portray shading of lantana by sal trees, aiming at a more realistic explanation of the lantana dominated cover. Furthermore, SPOT-6-based classification accuracy matrix revealed that 179 pixels related to agriculture were assigned to the built-up class, while 44 pixels of built-up were classified as agriculture. This is presumably related to the similarities in spectral signature characteristics of fallow land and built-up classes [30]. However, in the case of RapidEye, a negligible misclassification was observed between agriculture and built-up due to an additional red-edge band, which is able to precisely separate agriculture compared to the red band of RapidEye data [64].

Sal trees and lantana areas were occasionally misclassified (Tables 3 and 4). In SPOT-6 and RapidEye data, 224 and 350 pixels of lantana were assigned to sal trees class, respectively (Tables 3 and 4). These misclassified pixels mostly belonged to highly dense forest stands, thus the spectral signature and elevation from VHRSI DSM were not able to accurately discriminate lantana, which is mainly located in the understory, from sal tree stands. This resulted in cross-classification of lantana and sal tree classes. Lantana exhibited a kappa coefficient of $84.84 \%$ and $81.13 \%$, whereas user's accuracy was $96.3 \%$ and $92.6 \%$ for SPOT-6 and RapidEye, respectively. VHR SPOT-6-based classification returned the second highest user's accuracy among all other classes compared to RapidEye when combined with very high spatial resolution DSM. In the case of RapidEye, user's accuracy of agriculture was the highest due to ability of the additional red-edge band to more precisely discriminate agriculture from sal trees and grasses. This confirmed the advantage of the applied classification for high spatial resolution multispectral data over medium and coarser spatial resolution satellite data. This is in agreement with former studies related to RF classification of VHR data such as WV-2 (2 m) for boreal forest habitats mapping [65], RapidEye (5 m) for classification of insect defoliation levels with help from the red-edge band, IKONOS (4 m) for tree health identification [66] and Pléiades-1B (2 m) for classification of wetland land-cover in arid regions [67]. 
Table 3. Classification accuracy matrix for SPOT-6.

\begin{tabular}{|c|c|c|c|c|c|c|c|c|c|c|}
\hline \multirow{2}{*}{$\begin{array}{l}\text { Reference } \\
\text { Data }\end{array}$} & \multicolumn{6}{|c|}{ Predicted Data } & \multirow{2}{*}{ Row Total } & \multirow{2}{*}{$\begin{array}{c}\text { Producer's } \\
\text { Accuracy (\%) }\end{array}$} & \multirow{2}{*}{$\begin{array}{c}\text { User's } \\
\text { Accuracy (\%) }\end{array}$} & \multirow{2}{*}{$\begin{array}{c}\text { Class } \\
\text { Error (\%) }\end{array}$} \\
\hline & Built-Up & Agri-culture & Sal Tree & Lantana & Shadow & Water & & & & \\
\hline Built-up & 945 & 44 & 0 & 1 & 0 & 11 & 1001 & 94.41 & 78.16 & 3.59 \\
\hline Agri-culture & 179 & 806 & 8 & 1 & 7 & 0 & 1001 & 80.52 & 85.47 & 1.79 \\
\hline Sal tree & 0 & 1 & 985 & 13 & 2 & 0 & 1001 & 98.40 & 80.94 & 3.67 \\
\hline Lantana & 12 & 3 & 224 & 703 & 60 & 0 & 1002 & 70.16 & 96.30 & 1.68 \\
\hline Shadow & 0 & 81 & 0 & 5 & 770 & 0 & 856 & 89.95 & 91.78 & 1.29 \\
\hline Water & 73 & 8 & 0 & 7 & 0 & 913 & 1001 & 91.21 & 98.81 & 2.98 \\
\hline $\begin{array}{c}\text { Column } \\
\text { Total }\end{array}$ & 1209 & 943 & 1217 & 730 & 839 & 924 & 5122 & & & \\
\hline
\end{tabular}

Table 4. Classification accuracy matrix for RapidEye.

\begin{tabular}{|c|c|c|c|c|c|c|c|c|c|c|}
\hline \multirow{2}{*}{$\begin{array}{l}\text { Reference } \\
\text { Data }\end{array}$} & \multicolumn{6}{|c|}{ Predicted Data } & \multirow{2}{*}{ Row Total } & \multirow{2}{*}{$\begin{array}{c}\text { Producer's } \\
\text { Accuracy (\%) }\end{array}$} & \multirow{2}{*}{$\begin{array}{c}\text { User's } \\
\text { Accuracy (\%) }\end{array}$} & \multirow{2}{*}{$\begin{array}{c}\text { Class } \\
\text { Error (\%) }\end{array}$} \\
\hline & Built-Up & Agri-culture & Sal Tree & Lantana & Shadow & Water & & & & \\
\hline Built-up & 261 & 7 & 8 & 1 & 0 & 0 & 277 & 94.22 & 93.55 & 2.28 \\
\hline Agri-culture & 4 & 522 & 48 & 1 & 0 & 7 & 582 & 89.69 & 97.57 & 2.29 \\
\hline Sal tree & 7 & 3 & 935 & 37 & 19 & 0 & 1001 & 93.41 & 69.11 & 2.69 \\
\hline Lantana & 0 & 3 & 350 & 601 & 48 & 0 & 1002 & 59.98 & 92.60 & 5.31 \\
\hline Shadow & 0 & 0 & 12 & 9 & 53 & 0 & 74 & 71.62 & 41.09 & 13.60 \\
\hline Water & 7 & 0 & 0 & 0 & 9 & 986 & 1002 & 98.40 & 99.30 & 2.88 \\
\hline $\begin{array}{c}\text { Column } \\
\text { Total }\end{array}$ & 279 & 535 & 1353 & 649 & 129 & 993 & 3358 & & & \\
\hline
\end{tabular}

The OOB error of SPOT-6, i.e., the internal consistency of the RF model for classifying the training data, varied between $1.3 \%$ and $3.7 \%$, with an average OOB estimate of error of $2.5 \%$. In addition, the applied 5-fold cross-validation resulted in $97.2 \mathrm{OA}$ and $96.68 \%$ user's accuracy for lantana. A higher average OOB error of RapidEye was observed (3.58\%) due to higher class error $(13.6 \%)$ and lower user's accuracy (41.1\%) of shadow (Table 4). The applied 5-fold cross-validation resulted in $96.47 \%$ OA and $94.67 \%$ user's accuracy for lantana. Overall, the classification of VHR SPOT-6 and RapidEye data achieved practically plausible results, which agreed with previous results of VHR data classification for detailed land cover (forests and plant species) mapping [27,33,68].

We used DSM (Figure 3) as an additional parameter in RF classification algorithm, which showed the variation in elevation from 400 to $1500 \mathrm{~m}$. However, the elevation of Lachhiwala and Thano forests spans between 450 and $750 \mathrm{~m}$ (Figure 3). Since forest areas are heterogeneous and complex due to variations in tree height and stand density [69], high-resolution optical-based DSM can introduce different structural characteristics among understory and upperstory vegetation, which depends on the effects caused by tree orientation and sunlight [70]. In addition, shaded areas in high-density forest stands may reduce the quality of DSM due to variation in topography and sun angle [13]. One may also note the effect of seasonality on the quality of DSM [71]. We selected the SPOT scene within the leaf fall season of April, thus it resulted in partial extraction of ground and tree canopy by the applied image matching algorithm. Our results suggested that the classification accuracy increased by incorporating DSM from optical VHRSI SPOT-6 (at 1.5-m spatial resolution) for mapping understory (lantana) and upperstory (sal trees) vegetation. This was in agreement with previous studies, which highlighted the impact of elevation data as ancillary information in the RF classifier approach to differentiate spectrally similar objects and accuracy enhancement of land-cover mapping [72,73]. In addition, previous studies also reported that fine-scale DSM generated from VHRSI data may be used as an alternative to LiDAR data in areas with restricted accessibility $[27,74]$. Thus, very accurate large coverage DSM generation could be possible with the availability of stereo imaging capable VHR satellites and these may provide cost-effective solutions compared to expensive LiDAR technology for automatic classification of complex forest environments and delineation of understory plant species from upperstory vegetation. 


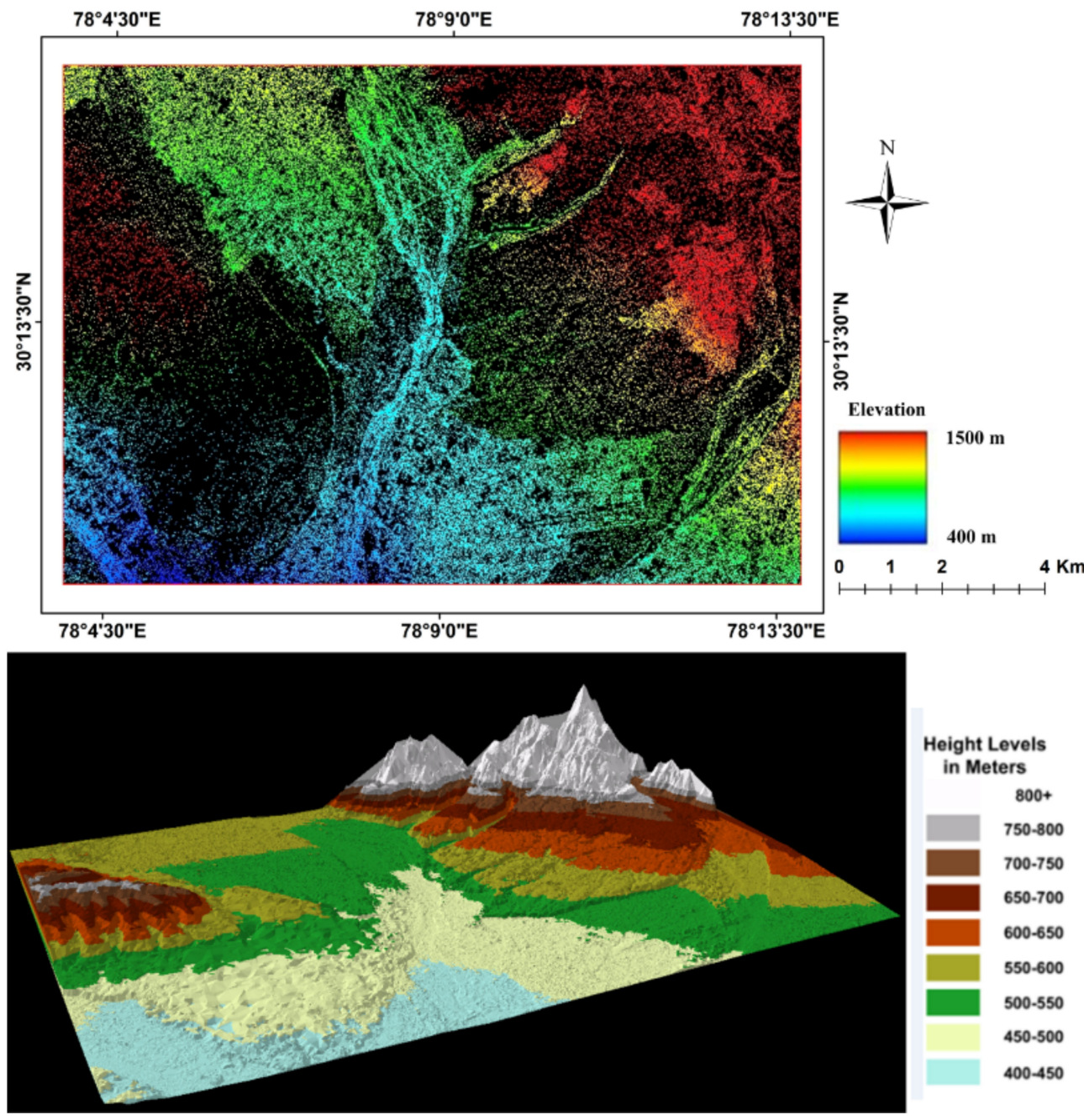

Figure 3. DSM of the study area represented by point cloud data (panel a) and 3D view (panel b). Black color in point cloud data represent NA values.

Overall, our results suggested the ability of SPOT-6 and RapidEye imageries to segregate lantana from dry sal trees and other land surface classes. However, the presence of lantana in forest areas generally increased confusion in the overall spectral signature within each pixel due to its competitive nature when growing with other vegetation types. Furthermore, comparisons across elevation gradients (see Figures $3 \mathrm{~b}$ and 4 ) demonstrated that the classification of lantana and other land surface classes performed better in lower elevation areas (from 400 to $600 \mathrm{~m}$ a.s.l.). 

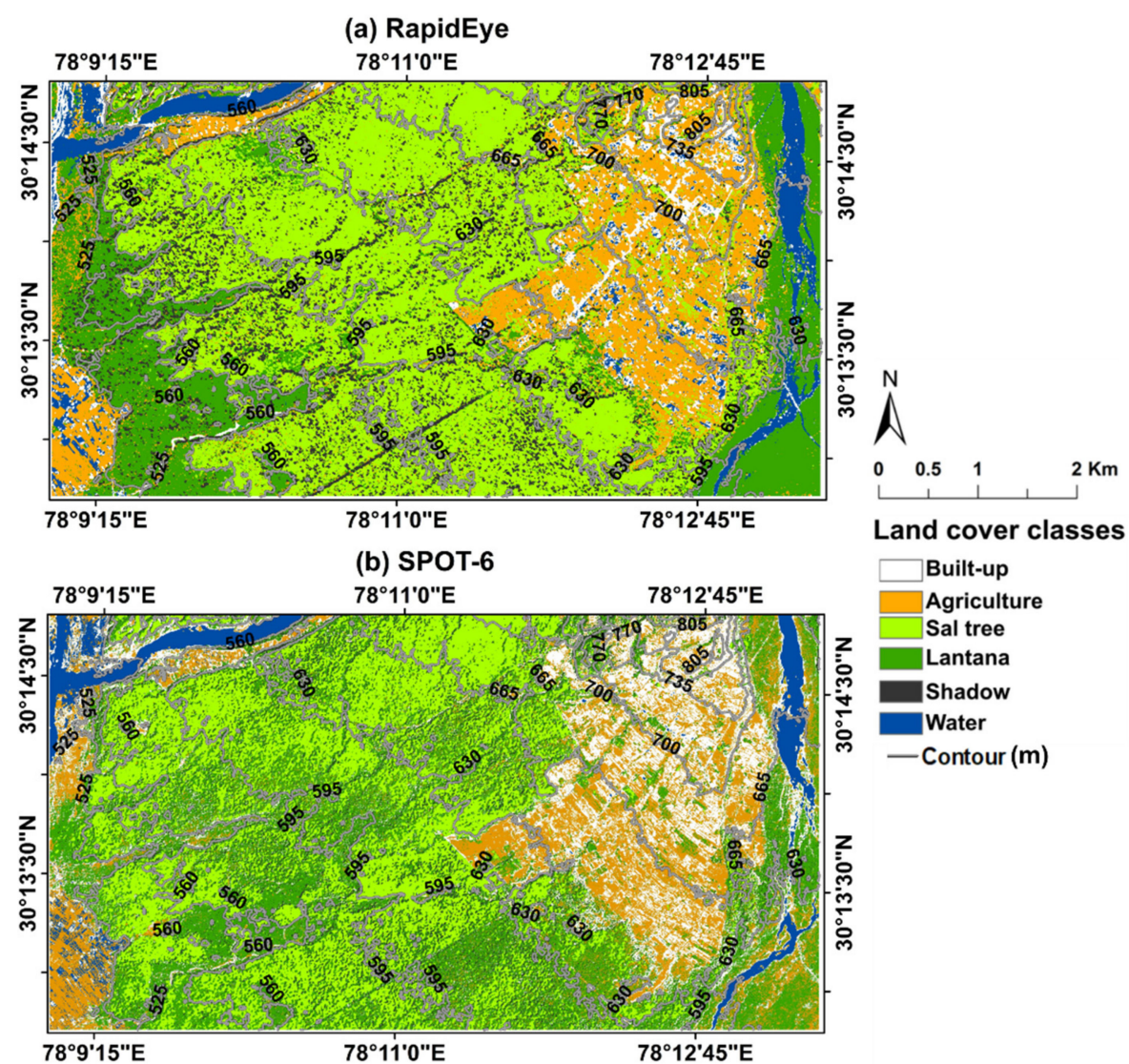

Figure 4. RF classification of (a) RapidEye and (b) SPOT-6 multispectral imageries for smaller extent.

\subsection{Variable Importance}

As expected from frequent field visits, DSM-derived elevation was among the most significant contributors to classification performance, although its influence was somewhat more pronounced when classifying RapidEye data. The overall importance of elevation was in line with a previous study [71] that applied Landsat multi-spectral data with ancillary data such as elevation (10 m contour interval), slope, and aspect for land-cover classification of mountainous areas. Accordingly, the DSM-derived elevation and slope combined with NDVI were the most important predictors for discriminating lantana (Figure 5). Whereas topographic information could be derived from a variety of 3D data sources, here we relied on those extracted from VHRSI due to a general absence of crown-penetrating LiDAR data across our study region. However, this was entirely due to a practical rationale; a recent study [74] also suggested that DSMs derived from VHRSI (WV-3 with $0.5 \mathrm{~m}$ spatial resolution) during leaf-off conditions were generally comparable to the LiDAR bare-earth DTM and may be used in land cover classification of vegetation during leaf-off seasons. In addition, red-edge spectral information of RapidEye data was ranked high when discriminating understory lantana from agriculture and built-up land cover, compared with texture parameters. Similar results were observed in a previous study that combined red-edge and texture parameters for paddy-rice crop classification [75]. Nevertheless, our study suggested that additional spectral information introduced by the red-edge band of RapidEye has the potential to discriminate invasive plants from other land-cover classes in relatively complex heterogeneous forest environments. However, future tests are suggested with freely available Sentinel-2 multispectral data featuring three red-edge bands. 


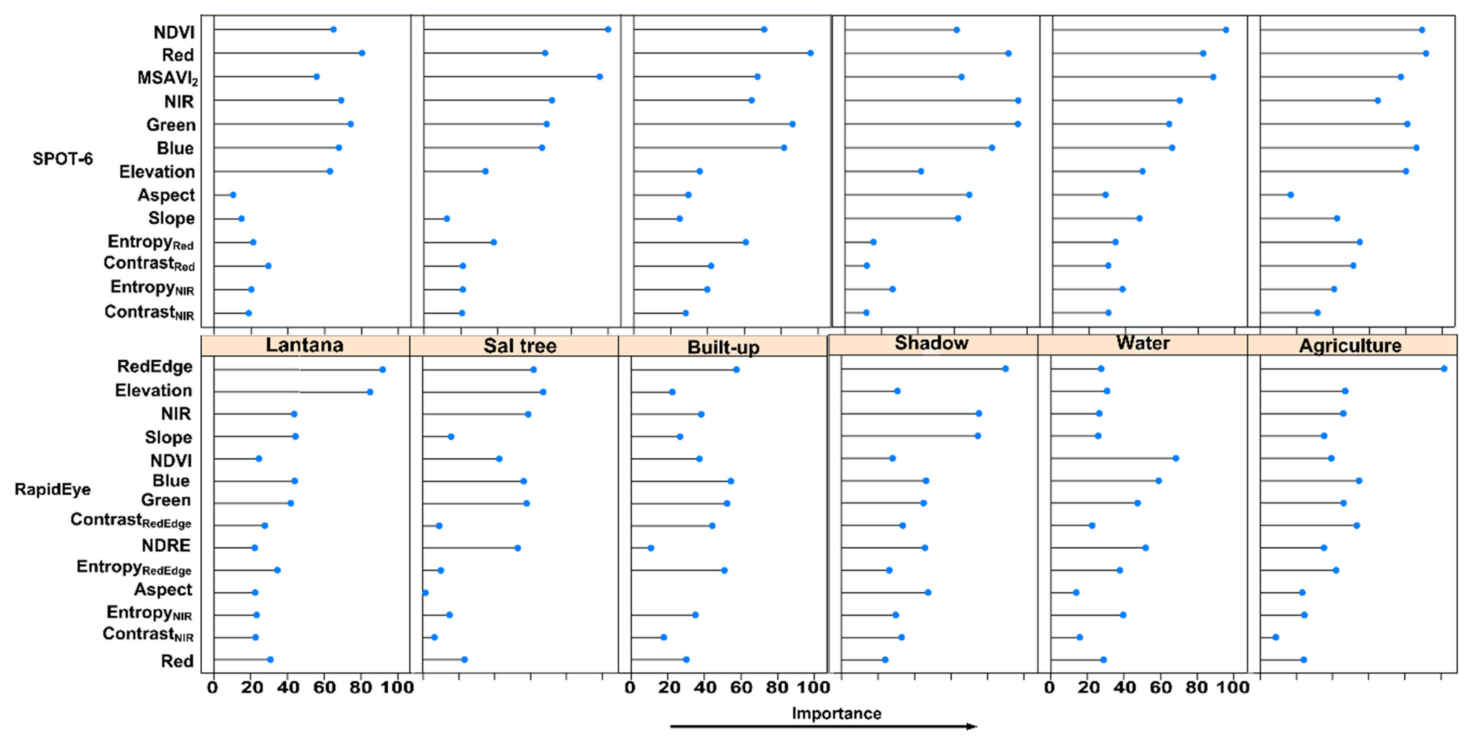

Figure 5. Variable importance shown as mean accuracy decrease (\% decrease in overall accuracy) for SPOT-6 and RapidEye-based classification.

\subsection{Landsat-8-Based Fractional Cover Maps for SPOT-6 and RapidEye}

The RF models based on the results of SPOT-6 calibrated with larger extent Landsat-8-based predictors explained $64.38 \%$ of the variance for lantana, and $71.67 \%$ for sal trees. Moreover, $37.96 \%$ variance for lantana and $55.63 \%$ variance for sal trees were observed with RapidEye fractional reference map as an input (Table 5). The lower spatial resolution of Rapideye $(5 \mathrm{~m})$ compared with SPOT-6 $(1.5 \mathrm{~m})$ data resulted in lower observed variance when RapidEye was calibrated with larger extent Landsat-8. Furthermore, $40 \%$ fractional coverage of lantana was observed in lower elevation zones (400 to $500 \mathrm{~m}$ ) from the classifications of Landsat-based upscaled maps (Figure 6) for both SPOT-6 and RapidEye fractional reference inputs. This result is in agreement with previous studies $[30,63]$ that observed the dominance of lantana in open lowland (400-500 m a.s.1.) areas compared to the high-elevation (>500 $\mathrm{m}$ a.s.l.) sal-dominated areas.

Table 5. Fractional cover statistics for lantana and forest classes. Probability of significant relevance codes are $0.05<p:{ }^{* * *}, p<0.001$.

\begin{tabular}{ccccccc}
\hline \multirow{2}{*}{ Class } & \multicolumn{3}{c}{ SPOT-6 } & \multicolumn{3}{c}{ RapidEye } \\
\cline { 2 - 7 } & $\boldsymbol{R}^{\mathbf{2}}$ & $\begin{array}{c}\text { RMSE } \\
\mathbf{( \% )}\end{array}$ & $\begin{array}{c}\text { Variance } \\
\mathbf{( \% )}\end{array}$ & $\boldsymbol{R}^{\mathbf{2}}$ & $\begin{array}{c}\text { RMSE } \\
\mathbf{( \% )}\end{array}$ & $\begin{array}{c}\text { Variance } \\
\mathbf{( \% )}\end{array}$ \\
\hline Lantana & $0.92^{* * *}$ & 7.22 & 64.38 & $0.85^{* * *}$ & 11.8 & 37.96 \\
Sal trees & $0.94^{* * *}$ & 7.73 & 71.67 & $0.86^{* * *}$ & 12.1 & 55.63 \\
\hline
\end{tabular}

The most important variables for lantana estimation were the spectral reflectance of Landsat- 8 (NIR, green and red) and April NDVI. Similar features were important for the sal trees models, with the main difference being the increased importance of NDVI. Higher $R^{2}$ and lower RMSE were observed for reference fractional cover data of SPOT- 6 when compared to RapidEye for both lantana and sal trees (Table 5). The accuracy of fractional cover maps increased when higher spatial resolution maps $(1.5 \mathrm{~m})$ were used as a reference. This approach is in line with a previous study [33], which also suggested developing fractional cover maps for European spruce (Picea abies L.) and Scots pine (Pinus sylvestris L.) using RF regression by combining VHR WV-2 $(2 \mathrm{~m})$ and medium spatial resolution Landsat time series data.

Our results were able to generate fractional cover maps in a heterogeneous environment when other classes were mixed with sal trees, especially soil-dominated and understory land covers such 
as lantana, agriculture and bare soil in the dry season. This was in agreement with an earlier study focusing on canopy fractional cover degradation mapping in a heterogeneous tropical forest of Brazil by combining Landsat ETM+ and VHR IKONOS data [35]. This research suggested the importance of reducing the mixed pixel problem in medium spatial resolution classification and the necessity of calibrating Landsat-derived results by the established model based on the combination of Landsat, SPOT-6, and RapidEye. The combination of open Landsat TM (30 m) and MODIS (250 m) were also used by [76] to map a forest and extract three fractions of vegetation, shadow and soil, to highlight deforestation. Since our approach included expensive VHR data, time series analysis could be limited by high cost. However, this type of analysis could be tested for a combination of open time series Sentinel-2 (10-20 m spatial resolution) and Landsat-8 (30 m spatial resolution) datasets.
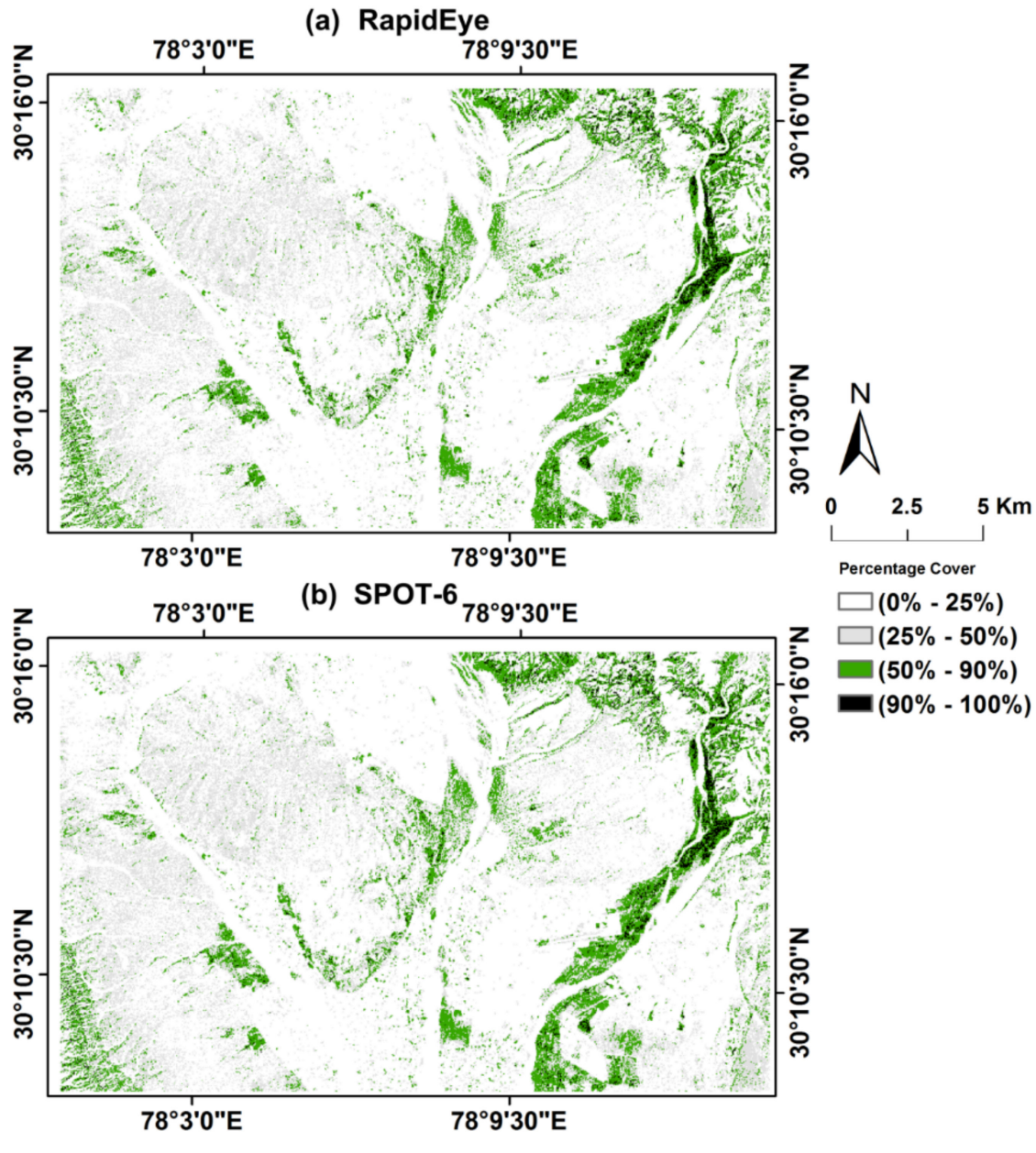

Figure 6. Landsat- 8 classification for lantana within fractional cover thresholds $(0 \%-25 \%, 25 \%-50 \%$, $50 \%-90 \%, 90 \%-100 \%$ ) for (a) RapidEye and (b) SPOT-6 data.

\section{Conclusions}

This study presented a fractional cover approach to predicting the proportion of lantana cover for a large area based on the spectral reflectance of medium spatial resolution multispectral Landsat- 8 imagery in a Western Himalayan region of India. Training data for fractional cover analysis was classified with smaller extent VHR SPOT-6 $(1.5 \mathrm{~m})$ and RapidEye $(5 \mathrm{~m})$ imageries by adding VHRSI information derived from SPOT-6 data. Results of VHR maps showed $87.38 \%$ and $85.27 \%$ overall accuracy for SPOT-6 and RapidEye, respectively. Our observations suggested that 3D information from VHRSI optical satellite data played a crucial role in distinguishing understory (in our case lantana) from upperstory vegetation, being also a valid alternative to costly LiDAR data. We conclude that classification accuracy improves at increasing spatial resolution, with decreasing mixed pixel problems 
for fractional cover maps when spatializing data on larger geographical areas. This approach is consistent and reliable for large mountainous biodiversity hotspots, where direct field observations are prevented by harsh climatic conditions. This approach may be implemented for other species mapping over larger areas by combining freely available Sentinel-2 and Landsat datasets.

Author Contributions: S.K., H.L., and S.R. designed the research. S.K. and H.L. provided the satellite and other required data sources. S.K. conducted the data processing. S.K., H.L. and S.R. performed the analysis of the results and the statistical interpretation. S.K. performed the code programming, supported by H.L., S.K. and H.L. wrote the first draft of paper. H.L., S.R. and S.K.G. commented on the draft and all authors finalized it. H.L. and S.K. were corresponding authors.

Funding: The SPOT-6 multispectral and stereo pair dataset were funded by European Space Agency (ESA) with project id: 33429 and and RapidEye datasets were funded by RapidEye Science Archive (RESA) with project id: 00184 .

Acknowledgments: We thank U.S. Geological Survey (USGS) EROS data center for Landsat-8 data, Department of Remote Sensing of University of Wuerzburg, Germany for providing a research residency to S. Khare, and A. Garside for checking the English text.

Conflicts of Interest: The authors declare no conflict of interest. The funders had no role in the design of the study; in the collection, analyses, or interpretation of data; in the writing of the manuscript, or in the decision to publish the results.

\section{References}

1. Duffy, J.E. Why biodiversity is important to the functioning of real-world ecosystems. Front. Ecol. Environ. 2009, 7, 437-444. [CrossRef]

2. Cardinale, B.J.; Duffy, J.E.; Gonzalez, A.; Hooper, D.U.; Perrings, C.; Venail, P.; Narwani, A.; Mace, G.M.; Tilman, D.; Wardle, D.A.; et al. Biodiversity loss and its impact on humanity. Nature 2012, 486, 59-67. [CrossRef]

3. Pasher, J.; Smith, P.A.; Forbes, M.R.; Duffe, J. Terrestrial ecosystem monitoring in Canada and the greater role for integrated earth observation. Environ. Rev. 2013, 22, 179-187. [CrossRef]

4. Turner, W.; Spector, S.; Gardiner, N.; Fladeland, M.; Sterling, E.; Steininger, M. Remote sensing for biodiversity science and conservation. Trends Ecol. Evol. 2003, 18, 306-314. [CrossRef]

5. Buchanan, G.M.; Nelson, A.; Mayaux, P.; Hartley, A.; Donald, P.F. Delivering a Global, Terrestrial, Biodiversity Observation System through Remote Sensing. Conserv. Boil. 2009, 23, 499-502. [CrossRef] [PubMed]

6. Leidner, A.K.; Brink, A.B.; Szantoi, Z. Leveraging Remote Sensing for Conservation Decision Making. Eos Trans. Am. Geophys. Union 2013, 94, 508. [CrossRef]

7. Nagendra, H.; Rocchini, D.; Ghate, R.; Sharma, B.; Pareeth, S. Assessing Plant Diversity in a Dry Tropical Forest: Comparing the Utility of Landsat and Ikonos Satellite Images. Remote Sens. 2010, 2, 478-496. [CrossRef]

8. Pettorelli, N.; Laurance, W.F.; O’Brien, T.G.; Wegmann, M.; Nagendra, H.; Turner, W. Satellite remote sensing for applied ecologists: Opportunities and challenges. J. Appl. Ecol. 2014, 51, 839-848. [CrossRef]

9. Lausch, A.; Bannehr, L.; Beckmann, M.; Boehm, C.; Feilhauer, H.; Hacker, J.; Heurich, M.; Jung, A.; Klenke, R.; Neumann, C.; et al. Linking Earth Observation and taxonomic, structural and functional biodiversity: Local to ecosystem perspectives. Ecol. Indic. 2016, 70, 317-339. [CrossRef]

10. Singh, J.S.; Roy, P.S.; Murthy, M.S.R.; Jha, C.S. Application of landscape ecology and remote sensing for assessment, monitoring and conservation of biodiversity. J. Indian Soc. Remote Sens. 2010, 38, 365-385. [CrossRef]

11. Joshi, P.K.; Rawat, G.S.; Padilya, H.; Roy, P.S. Biodiversity Characterization in Nubra Valley, Ladakh with Special Reference to Plant Resource Conservation and Bioprospecting. Biodivers. Conserv. 2006, 15, 4253-4270. [CrossRef]

12. Lim, K.; Treitz, P.; Wulder, M.; St-Onge, B.; Flood, M.; St-Onge, B. LiDAR remote sensing of forest structure. Prog. Phys. Geogr. Earth Environ. 2003, 27, 88-106. [CrossRef]

13. Latifi, H.; Heurich, M.; Hartig, F.; Müller, J.; Krzystek, P.; Jehl, H.; Dech, S. Estimating over- and understorey canopy density of temperate mixed stands by airborne LiDAR data. Forestry 2015, 89, 69-81. [CrossRef]

14. Vastaranta, M.; Wulder, M.A.; White, J.C.; Pekkarinen, A.; Tuominen, S.; Ginzler, C.; Kankare, V.; Holopainen, M.; Hyyppä, J.; Hyyppä, H. Airborne laser scanning and digital stereo imagery measures of forest 
structure: Comparative results and implications to forest mapping and inventory update. Can. J. Remote Sens. 2013, 39, 382-395. [CrossRef]

15. Aguilar, M.A.; Saldana, M.D.M.; Aguilar, F.J. Generation and Quality Assessment of Stereo-Extracted DSM from GeoEye-1 and WorldView-2 Imagery. IEEE Trans. Geosci. Remote Sens. 2014, 52, 1259-1271. [CrossRef]

16. Piermattei, L.; Marty, M.; Karel, W.; Ressl, C.; Hollaus, M.; Ginzler, C.; Pfeifer, N. Impact of the Acquisition Geometry of Very High-Resolution Pléiades Imagery on the Accuracy of Canopy Height Models over Forested Alpine Regions. Remote Sens. 2018, 10, 1542. [CrossRef]

17. Zhu, Z.; Evans, D.L. US forest types and predicted percent forest cover from AVHRR data. PE RS Photogramm. Eng. Remote Sens. 1994, 60, 525-531.

18. Hansen, M.C.; Potapov, P.V.; Moore, R.; Hancher, M.; Turubanova, S.A.; Tyukavina, A.; Thau, D.; Stehman, S.V.; Goetz, S.J.; Loveland, T.R.; et al. High-Resolution Global Maps of 21st-Century Forest Cover Change. Science 2013, 342, 850-853. [CrossRef]

19. Kim, D.-H.; Sexton, J.O.; Noojipady, P.; Huang, C.; Anand, A.; Channan, S.; Feng, M.; Townshend, J.R. Global, Landsat-based forest-cover change from 1990 to 2000. Remote Sens. Environ. 2014, 155, 178-193. [CrossRef]

20. Kumar, A.S.; Radhika, T.; Saritha, P.; Keerthi, V.; Anjani, R.N.; Kumar, M.S.; Sekhar, K.S.; Satyanarayana, P.; Sudha, M.S.N.; Sai, M.S.; et al. Generation of Vegetation Fraction and Surface Albedo Products Over India from Ocean Colour Monitor (OCM) Data Onboard Oceansat-2. J. Indian Soc. Remote Sens. 2014, 42, 701-709. [CrossRef]

21. Pérez-Hoyos, A.; García-Haro, F.; San-Miguel-Ayanz, J. Conventional and fuzzy comparisons of large scale land cover products: Application to CORINE, GLC2000, MODIS and GlobCover in Europe. ISPRS J. Photogramm. Remote Sens. 2012, 74, 185-201. [CrossRef]

22. Carleer, A.P.; Wolff, E. Urban land cover multi-level region-based classification of VHR data by selecting relevant features. Int. J. Remote Sens. 2006, 27, 1035-1051. [CrossRef]

23. Mora, B.; Wulder, M.A.; White, J.C. Identifying leading species using tree crown metrics derived from very high spatial resolution imagery in a boreal forest environment. Can. J. Remote Sens. 2010, 36, 332-344. [CrossRef]

24. Kim, S.-R.; Lee, W.-K.; Kwak, D.-A.; Biging, G.S.; Gong, P.; Lee, J.-H.; Cho, H.-K. Forest Cover Classification by Optimal Segmentation of High Resolution Satellite Imagery. Sensors 2011, 11, 1943-1958. [CrossRef] [PubMed]

25. Immitzer, M.; Atzberger, C.; Koukal, T. Tree Species Classification with Random Forest Using Very High Spatial Resolution 8-Band WorldView-2 Satellite Data. Remote Sens. 2012, 4, 2661-2693. [CrossRef]

26. Waser, L.T.; Küchler, M.; Jütte, K.; Stampfer, T. Evaluating the Potential of WorldView-2 Data to Classify Tree Species and Different Levels of Ash Mortality. Remote Sens. 2014, 6, 4515-4545. [CrossRef]

27. Fassnacht, F.E.; Mangold, D.; Schäfer, J.; Immitzer, M.; Kattenborn, T.; Koch, B.; Latifi, H. Estimating stand density, biomass and tree species from very high resolution stereo-imagery-towards an all-in-one sensor for forestry applications? For. Int. J. For. Res. 2017, 90, 613-631. [CrossRef]

28. Kandwal, R.; Jeganathan, C.; Tolpekin, V.; Kushwaha, S.P.S. Discriminating the invasive species, 'Lantana' using vegetation indices. J. Indian Soc. Remote Sens. 2009, 37, 275-290. [CrossRef]

29. Kimothi, M.M.; Dasari, A. Methodology to map the spread of an invasive plant (Lantana camara L.) in forest ecosystems using Indian remote sensing satellite data. Int. J. Remote Sens. 2010, 31, 3273-3289. [CrossRef]

30. Khare, S.; Latifi, H.; Ghosh, S.K. Multi-scale assessment of invasive plant species diversity using Pléiades 1A, RapidEye and Landsat-8 data. Geocarto Int. 2018, 33, 681-698. [CrossRef]

31. Fassnacht, F.E.; Latifi, H.; Stereńczak, K.; Modzelewska, A.; Lefsky, M.; Waser, L.T.; Straub, C.; Ghosh, A. Review of studies on tree species classification from remotely sensed data. Remote Sens. Environ. 2016, 186, 64-87. [CrossRef]

32. Gairola, S.; Procheş, Ş.; Rocchini, D. High-resolution satellite remote sensing: A new frontier for biodiversity exploration in Indian Himalayan forests. Int. J. Remote Sens. 2013, 34, 2006-2022. [CrossRef]

33. Immitzer, M.; Böck, S.; Einzmann, K.; Vuolo, F.; Pinnel, N.; Wallner, A.; Atzberger, C. Fractional cover mapping of spruce and pine at 1 ha resolution combining very high and medium spatial resolution satellite imagery. Remote Sens. Environ. 2018, 204, 690-703. [CrossRef]

34. Metzler, J.W.; Sader, S.A. Model development and comparison to predict softwood and hardwood per cent cover using high and medium spatial resolution imagery. Int. J. Remote Sens. 2005, 26, 3749-3761. [CrossRef] 
35. Wang, C.; Qi, J.; Cochrane, M. Assessment of tropical forest degradation with canopy fractional cover from Landsat ETM+ and IKONOS imagery. Earth Interact. 2005, 9, 1-18. [CrossRef]

36. Donmez, C.; Berberoglu, S.; Erdogan, M.A.; Tanriover, A.A.; Cilek, A. Response of the regression tree model to high resolution remote sensing data for predicting percent tree cover in a Mediterranean ecosystem. Environ. Monit. Assess. 2015, 187, 4. [CrossRef] [PubMed]

37. Champion, S.H.; Seth, S.K. A Revised Survey of the Forest Types of India; Manager of Publications: Delhi, Indian, 1968.

38. Peel, M.C.; Finlayson, B.L.; McMahon, T.A. Updated world map of the Köppen-Geiger climate classification. Hydrol. Earth Syst. Sci. 2007, 11, 1633-1644. [CrossRef]

39. Khare, S.; Latifi, H.; Ghosh, K. Phenology analysis of forest vegetation to environmental variables during pre-and post-monsoon seasons in western Himalayan region of India. ISPRS Int. Arch. Photogramm. Remote Sens. Spat. Inf. Sci. 2016, 41, 15-19. [CrossRef]

40. Khare, S.; Ghosh, S.K.; Latifi, H.; Vijay, S.; Dahms, T. Seasonal-based analysis of vegetation response to environmental variables in the mountainous forests of Western Himalaya using Landsat 8 data. Int. J. Remote Sens. 2017, 38, 4418-4442. [CrossRef]

41. Chander, G.; Haque, M.; Sampath, A.; Brunn, A.; Trosset, G.; Hoffmann, D.; Roloff, S.; Thiele, M.; Anderson, C. Radiometric and geometric assessment of data from the RapidEye constellation of satellites. Int. J. Remote Sens. 2013, 34, 5905-5925. [CrossRef]

42. Richter, R.; Center, R.S.D. ATCOR: Atmospheric and Topographic Correction. DLR-German Aerospace Center; Remote Sensing Data Center: Oberpfaffenhofen, Germany, 2004.

43. Kwoh, L.K.; Liew, S.C.; Xiong, Z. Automatic DEM generation from satellite image. In Proceedings of the 25th Asian Conference \& 1st Asian Space Conference on Remote Sensing, Chiang Mai, Thailand, 22-25 November 2004; pp. 22-26.

44. Rottensteiner, F.; Weser, T.; Fraser, C.S. November. Georeferencing and orthoimage generation from long strips of ALOS imagery. In Proceedings of the 2nd ALOS PI Symposium, Rhodes, Greece, 3-7 November 2008.

45. Poon, J.; Fraser, C.S.; Chunsun, Z.; Li, Z.; Gruen, A. Quality Assessment of Digital Surface Models Generated From IKONOS Imagery. Photogramm. Rec. 2005, 20, 162-171. [CrossRef]

46. Toutin, T. Review article: Geometric processing of remote sensing images: Models, algorithms and methods. Int. J. Remote Sens. 2004, 25, 1893-1924. [CrossRef]

47. Krauß, T.; Reinartz, P.; Lehner, M.; Schroeder, M.; Stilla, U. DEM generation from very high resolution stereo satellite data in urban areas using dynamic programming. International Archives of the Photogrammetry. Remote Sens. Spat. Inf. Sci. 2005, 36, 1.

48. Breiman, L. Random forests. Mach. Learn. 2001, 45, 5-32. [CrossRef]

49. Belgiu, M.; Drăgut, L. Random forest in remote sensing: A review of applications and future directions. ISPRS J. Photogramm. Remote Sens. 2016, 114, 24-31. [CrossRef]

50. Leutner, B.; Horning, N. RStoolbox: Tools for Remote Sensing Data Analysis; R Package Version 0.1; R Package Vignette: Madison, WI, USA, 2017; Volume 8.

51. Core Team, R.C. R: A Language and Environment for Statistical Computing; R Foundation for Statistical Computing: Vienna, Austria, 2013.

52. Wegmann, M.; Leutner, B.; Dech, S. (Eds.) Remote Sensing and GIS for Ecologists: Using Open Source Software; Pelagic Publishing Ltd.: Exeter, UK, 2016.

53. Zvoleff, A. Glcm: Calculate Textures from Grey-Level Co-Occurrence Matrices GLCMs) in R; R Package Version 1.0; R Package Vignette: Madison, WI, USA, 2015.

54. Gamon, J.A.; Kovalchuk, O.; Wong, C.Y.S.; Harris, A.; Garrity, S.R. Monitoring seasonal and diurnal changes in photosynthetic pigments with automated PRI and NDVI sensors. Biogeosci. Discuss. 2015, 12, 2947-2978. [CrossRef]

55. Modzelewska, A.; Stereńczak, K.; Mierczyk, M.; Maciuk, S.; Bałazy, R.; Zawiła-Niedźwiecki, T. Sensitivity of vegetation indices in relation to parameters of Norway spruce stands. Folia For. Pol. 2017, 59, 85-98. [CrossRef]

56. Cammarano, D.; Fitzgerald, G.J.; Casa, R.; Basso, B. Assessing the Robustness of Vegetation Indices to Estimate Wheat $\mathrm{N}$ in Mediterranean Environments. Remote Sens. 2014, 6, 2827-2844. [CrossRef]

57. Silleos, N.G.; Alexandridis, T.K.; Gitas, I.Z.; Perakis, K. Vegetation Indices: Advances Made in Biomass Estimation and Vegetation Monitoring in the Last 30 Years. Geocarto Int. 2006, 21, 21-28. [CrossRef]

58. Breiman, L. Bagging predictors. Mach. Learn. 1996, 24, 123-140. [CrossRef] 
59. Provost, F.; Kohavi, R. Glossary of terms. J. Mach. Learn. 1998, 30, 271-274. [CrossRef]

60. Evans, J.S.; Murphy, M.A.; Holden, Z.A.; Cushman, S.A. Modeling species distribution and change using random forest. In Predictive Species and Habitat Modeling in Landscape Ecology; Springer: New York, NY, USA, 2011; pp. 139-159.

61. Fry, J.A.; Xian, G.; Jin, S.M.; Dewitz, J.A.; Homer, C.G.; Yang, L.M.; Barnes, C.A.; Herold, N.D.; Wickham, J.D. Completion of the 2006 national land cover database for the conterminous United States. Photogramm. Eng. Remote Sens. 2011, 77, 858-864.

62. Ismail, M.H.; Jusoff, K. Satellite data classification accuracy assessment based from reference dataset. Int. J. Comput. Inf. Sci. Eng. 2008, 2, 96-102.

63. Mandal, G.; Joshi, S.P. Eco-physiology and habitat invisibility of an invasive, tropical shrub (Lantana Camara) in western Himalayan forests of India. For. Sci. Technol. 2015, 11, 182-196.

64. Massetti, A. Assessing the effectiveness of RapidEye multispectral imagery for vegetation mapping in Madeira Island (Portugal). Eur. J. Remote Sens. 2016, 49, 643-672. [CrossRef]

65. Räsänen, A.; Rusanen, A.; Kuitunen, M.; Lensu, A. What makes segmentation good? A case study in boreal forest habitat mapping. Int. J. Remote Sens. 2013, 34, 8603-8627. [CrossRef]

66. Wang, H.; Zhao, Y.; Pu, R.; Zhang, Z. Mapping Robinia Pseudoacacia Forest Health Conditions by Using Combined Spectral, Spatial, and Textural Information Extracted from IKONOS Imagery and Random Forest Classifier. Remote Sens. 2015, 7, 9020-9044. [CrossRef]

67. Tian, S.; Zhang, X.; Tian, J.; Sun, Q. Random Forest Classification of Wetland Landcovers from Multi-Sensor Data in the Arid Region of Xinjiang, China. Remote Sens. 2016, 8, 954. [CrossRef]

68. Karlson, M.; Ostwald, M.; Reese, H.; Bazié, H.R.; Tankoano, B. Assessing the potential of multi-seasonal WorldView-2 imagery for mapping West African agroforestry tree species. Int. J. Appl. Earth Obs. Geoinf. 2016, 50, 80-88. [CrossRef]

69. Dash, J.P.; Watt, M.S.; Bhandari, S. Characterising forest structure using combinations of airborne laser scanning data, RapidEye satellite imagery and environmental variables. Forestry 2015, 89, 159-169. [CrossRef]

70. Qi, J.; Xie, D.; Yin, T.; Yan, G.; Gastellu-Etchegorry, J.-P.; Li, L.; Zhang, W.; Mu, X.; Norford, L.K. LESS: LargE-Scale remote sensing data and image simulation framework over heterogeneous 3D scenes. Remote Sens. Environ. 2019, 221, 695-706. [CrossRef]

71. Hyyppä, H.; Yu, X.; Hyyppä, J.; Kaartinen, H.; Kaasalainen, S.; Honkavaara, E.; Rönnholm, P. Factors affecting the quality of DTM generation in forested areas. Int. Arch. Photogramm. Remote Sens. Spat. Inf. Sci. 2005, 36, 85-90.

72. Gislason, P.O.; Benediktsson, J.A.; Sveinsson, J.R. Random Forests for land cover classification. Pattern Recognit. Lett. 2006, 27, 294-300. [CrossRef]

73. Corcoran, J.M.; Knight, J.F.; Gallant, A.L. Influence of Multi-Source and Multi-Temporal Remotely Sensed and Ancillary Data on the Accuracy of Random Forest Classification of Wetlands in Northern Minnesota. Remote Sens. 2013, 5, 3212-3238. [CrossRef]

74. DeWitt, J.D.; Warner, T.A.; Chirico, P.G.; Bergstresser, S.E. Creating high-resolution bare-earth digital elevation models (DEMs) from stereo imagery in an area of densely vegetated deciduous forest using combinations of procedures designed for lidar point cloud filtering. GIScience Remote Sens. 2017, 54, 1-21. [CrossRef]

75. Kim, H.-O.; Yeom, J.-M. Effect of red-edge and texture features for object-based paddy rice crop classification using RapidEye multi-spectral satellite image data. Int. J. Remote Sens. 2014, 35, 1-23. [CrossRef]

76. Lu, D.; Batistella, M.; Moran, E.; Hetrick, S.; Alves, D.; Brondizio, E. Fractional forest cover mapping in the Brazilian Amazon with a combination of MODIS and TM images. Int. J. Remote Sens. 2011, 32, 7131-7149. [CrossRef]

(C) 2019 by the authors. Licensee MDPI, Basel, Switzerland. This article is an open access article distributed under the terms and conditions of the Creative Commons Attribution (CC BY) license (http://creativecommons.org/licenses/by/4.0/). 